\title{
SPECTROPHOTOMETRIC DETERMINATION OF ULTRAMICRO AMOUNTS OF ANIONS BY CATALYTIC REACTIONS
}

Satori UTSUMI

College of Science and Technology, Nihon University, 1-8, Kanda-Surugadai, Chiyoda-ku, Tokyo 101

Kinetic methods based on the catalytic reaction have been reviewed for several anions. The methods are of extremely high sensitivity and selectivity, finding increasing application to trace analysis of materials of geochemical and environmental interest. The determination of iodine or nitrite is based on their catalytic effects on the color-fading of iron(III) thiocyanate complex in dilute nitric acid. The reaction allows the differential determination of iodide-iodine and iodate-iodine at trace level. Traces of bromide can be determined by its catalytic effect on the oxidation of iodine to iodate by permanganate in acid medium. The reaction $\left(2 \mathrm{NaN}_{3}+\mathrm{I}_{2} \longrightarrow 2 \mathrm{NaI}+3 \mathrm{~N}_{2}\right)$ is catalytically promoted in the presence of sulfur compounds. This catalytic reaction leads to the development of sensitive methods for the determination of thiosulfate, thiocyanate and sulfide. Improved catalytic methods for cyanide and fluoride are also quoted.

\section{Introduction}

Slow reactions under ordinary conditions can usually be made to proceed at a satisfactory rate in the presence of catalysts. In this respect catalytic methods for trace analysis differ from ordinary analytical methods such as titrimetric and photometric methods. In most of the catalytic reactions employed in analysis, quantitative measurements are made before the system reaches equilibrium. In order to determine the amount of the substance which acts as a catalyst, it is necessary to measure the rate of the indicator reaction or, in several cases, the length of its induction period. The rate of a chemical reaction can be measured from the amount of the reactant disappearing, or from the amount of the product being formed, in unit time. The reaction rate depends on the concentration of the catalyst which takes part in particular cycles.

Kinetic methods using catalytic reactions are of extremely high sensitivity and superior to the spectrophotometric method based on stoichiometric reactions. The sensitivity of the catalytic method or the minimum amount of catalyst that can be detected depends upon the relative rate of the catalyzed and uncatalyzed reactions and particularly upon the stability of this uncatalyzed reaction(reagent 
blank). In some cases, catalytic methods are characterized by their high selectivity.

Oxidation-reduction reactions form the largest group of catalytic reactions. Even though most of the catalytic methods reported are concerned with the determination of transition metal ions, a few involve catalysis by anions of non-metals.

There is a general approach that may be employed to estimate the concentration of the catalyst without obtaining the entire rate curve. The reaction is allowed to proceed for a strictly determined time interval and after this time interval the concentration of one of the substances in the solution is determined by measuring the absorbance. This is called a fixed time procedure. In this procedure a plot of absorbance vs the catalyst concentration yields a calibration curve for the determination of the catalyst. In practice the duration of the reaction is strictly controlled by stopping the reaction at a given moment by extraction of the reactant or by other methods.

The rate of a chemical reaction is strongly dependent on the concentration of the reactants and temperature. Therefore, for exact determinations, it is essential to control the concentration of the reagents and the reaction temperature.

The application of catalytic analysis is a relatively young field. It is definitely most useful for the determination of ultramicro amounts of chemical species.

The present author and co-workers have been exploiting many spectrophotometric catalytic methods for anions in ppb levels using a fixed time procedure. The application of these methods to geochemical and environmental materials has also been developed by Japanese scientists. Various catalytic methods investigated by Utsumi et al. will be summarized in the following sections.

2 Determination of Iodide and Iodate

The author et al. found that the reddish orange color of iron(III) thiocyanate complex which was formed by the reaction of potassium thiocyanate with an excess of iron(III) salt in a dilute nitric acid solution, faded very slowly owing to the oxidation of thiocyanate, but rapidly in the presence of minute amounts of iodide or iodate. This catalytic action of iodine turned out to be greatly affected by the presence of a small amount of nitrite. The catalytic reaction was studied extensively and a new micro-determination method for iodide established ${ }^{1)} 4^{4}$. The catalytic method has been applied to the determination of ultramicro amounts of iodine existing in the forms of both iodide and iodate ${ }^{5)}$. In the presence of more than $1000 \mathrm{ppm}$ chloride, iodate shows the same catalytic effect as iodide, and thus the total iodine can be determined in the presence of a large amount of chloride. Iodide in iodide-iodate mixture is first oxidized to iodine by the nitric acid solution of ammonium iron(III) sulfate, which is the reagent of this determination. The resulting iodine is removed by extraction with carbon tetrachloride. Iodate remaining in the aqueous layer quantitatively is then determined by the present method. The difference between the total iodine and the iodate-iodine gives the iodide-iodine.

2.1 Procedure for the determination of iodide ${ }^{4}$ )

The determination of iodide can be made by measuring the absorbance at $460 \mathrm{~nm}$ at a fixed time after the addition of $2.0 \mathrm{~cm}^{3}$ of ammonium iron(III) sulfate solu- 
tion (prepared by dissolving $6 \mathrm{~g}$ of the reagent in $100 \mathrm{~cm}^{3}$ of $7.0 \mathrm{~N} \mathrm{HNO}_{3}$ ) to 10.0 $\mathrm{cm}^{3}$ of the sample solution kept at a given temperature, to which $1.0 \mathrm{~cm}^{3}$ of a mix-

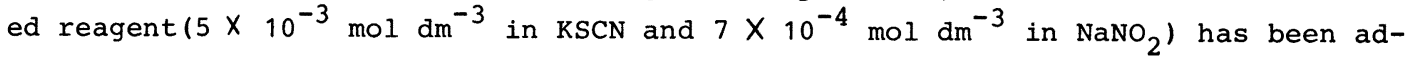
ded previously. By employing four different combinations of temperature and reaction time, iodide ions can be determined in four different concentration ranges:

$25{ }^{\circ} \mathrm{C}, 12 \mathrm{~min}: 0.5 \sim 10 \mathrm{ppm}, \quad 30{ }^{\circ} \mathrm{C}, 20 \mathrm{~min}: 0.05 \sim 1 \mathrm{ppm}$

$45^{\circ} \mathrm{C}, 25 \mathrm{~min}: 0.005 \sim 0.1 \mathrm{ppm}, 60{ }^{\circ} \mathrm{C}, 30 \mathrm{~min}: 0.0005 \sim 0.01 \mathrm{ppm}$.

The ppb levels of iodide in rain and river waters could be determined with the conditions of $60^{\circ} \mathrm{C}, 30 \mathrm{~min}$.

2.2 Some experimental results

2.2.1 The reaction rate Reaction rate curves shown in Fig. 1 were obtained by measuring the absorbance of the solution at different reaction time under the condition of procedure(2.1). As seen in Fig. 1, iodate showed a catalytic effect on the reaction rate different from iodide in the absence of chloride. The solution of $0.01 \mathrm{ppm}$ iodide becomes almost colorless after $30 \mathrm{~min}$. These results indicate that the sensitivity of the method increases with increasing reaction time.

\subsubsection{The effect of various}

ions Metal ions such as silver, mercury (I and II), manganese (II) and iron(II) interfered. Oxidizing or reducing anions also interfered with the determination of iodide ion.

\subsection{Applications}

2.3.1 Determination of iodide and iodate in sea water It is known that iodine in sea water exists in the form of both iodide and iodate. Yonehara ${ }^{6)}$ has reported the colorimetric determination of minute amounts of iodide and iodate in sea water by the catalytic method. In the presence of $2000 \mathrm{ppm}$ chloride, iodide and iodate show the same catalytic effect on the color-fading of the iron(III) thiocyanate. The total

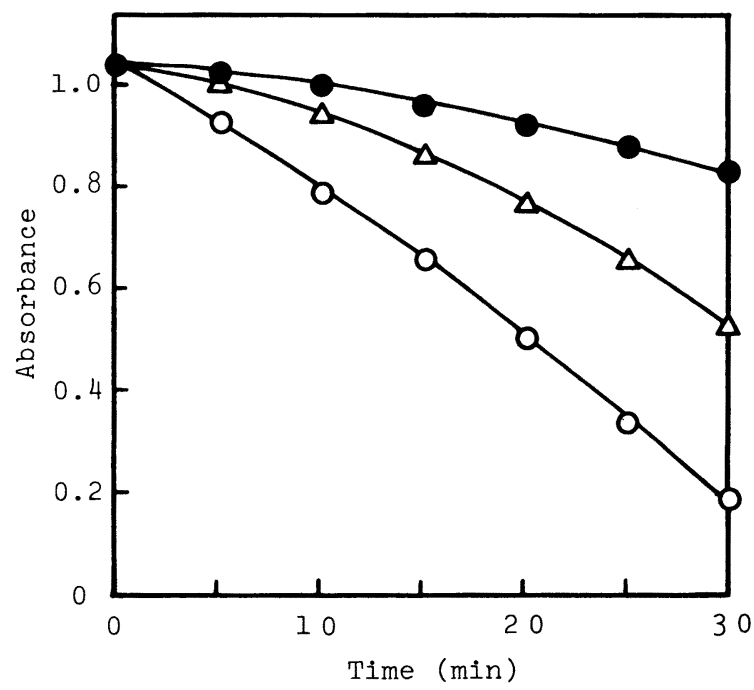

Fig. I Reaction rate curves (Temperature; $60{ }^{\circ} \mathrm{C}$ ) $\longrightarrow$ No $\mathrm{I}^{-}, \quad-0.01 \mathrm{ppm} \mathrm{I}^{-}$, iodine content in sea water is usually determined by the catalytic method using a sample diluted about ten times. The iodide in the sample is first oxidized to free iodine by sodium nitrite solution and nitric acid solution of ammonium iron(III) sulfate. The resulting free iodine is removed and the iodate is determined by a similar procedure. According to this method, the iodate and total iodine contents in sea water can be determined rapidly and accurately. It requires only about 2 $\mathrm{cm}^{3}$ of sea water.

2.3.2 Determination of iodine in silicate rocks Yonehara et al. ${ }^{7)}$ have developed a photometric method for the determination of minute amounts of iodine in 
silicate rocks. A rock is fused with potassium hydroxide, and the cake is treated with water and sulfuric acid. The iodine in the solution is reduced to iodide by sodium sulfite, and the iodide is then oxidized to free iodine by sodium nitrite. The free iodine thus obtained is extracted with carbon tetrachloride and then backextracted with a sodium hydroxide solution. The iodine in this aqueous layer is determined photometrically by the method based on the catalytic effect of iodine on the color-fading of iron(III) thiocyanate. Iodine as low as $0.007 \mu \mathrm{g}$ in a $1 \mathrm{~g}$ sample of silicate rocks can be determined in this way.

\section{Determination of Nitrite}

The author and co-workers ${ }^{8}$ ) found that the catalytic reaction described above (2.1) was characterized by an induction period, the length of which depended on the nitrite ion concentration. Detailed investigation on the behavior of nitrite ions have shown that the kinetic effect can be applied to the determination of nitrite ions.

\subsection{Procedure}

To $10.0 \mathrm{~cm}^{3}$ of the sample, $1 \mathrm{~cm}^{3}$ of the mixed reagent solution $\left(5 \times 10^{-3} \mathrm{~mol}^{\mathrm{dm}^{-3}}\right.$ in $\mathrm{KSCN}$ and $1 \times 10^{-3} \mathrm{~mol} \mathrm{\textrm {dm } ^ { - 3 }}$ in $\mathrm{KI}$ ) is added and kept in a water bath at $25.0{ }^{\circ} \mathrm{C}$ for $10 \mathrm{~min}$. The reaction is initiated by adding $2 \mathrm{~cm}^{3}$ of the iron(III) reagent solution(prepared by dissolving $6 \mathrm{~g}$ of ammonium iron(III) sulfate in $100 \mathrm{~cm}^{3}$ of $\left.7.0 \mathrm{~N} \mathrm{HNO}_{3}\right)$. The absorbance is measured at $460 \mathrm{~nm}$ at a certain time after the addition of the iron(III) reagent solution. By taking absorbance measurements at the reaction time of $7,13,19$ or $24 \mathrm{~min}$, nitrite ions in the concentration range of $0.5 \sim 10,0.05 \sim 1,0.005 \sim 0.1$ or $0.0005 \sim 0.01 \mathrm{ppm}$ can be determined respective$1 y$.

\subsection{Some experimental results}

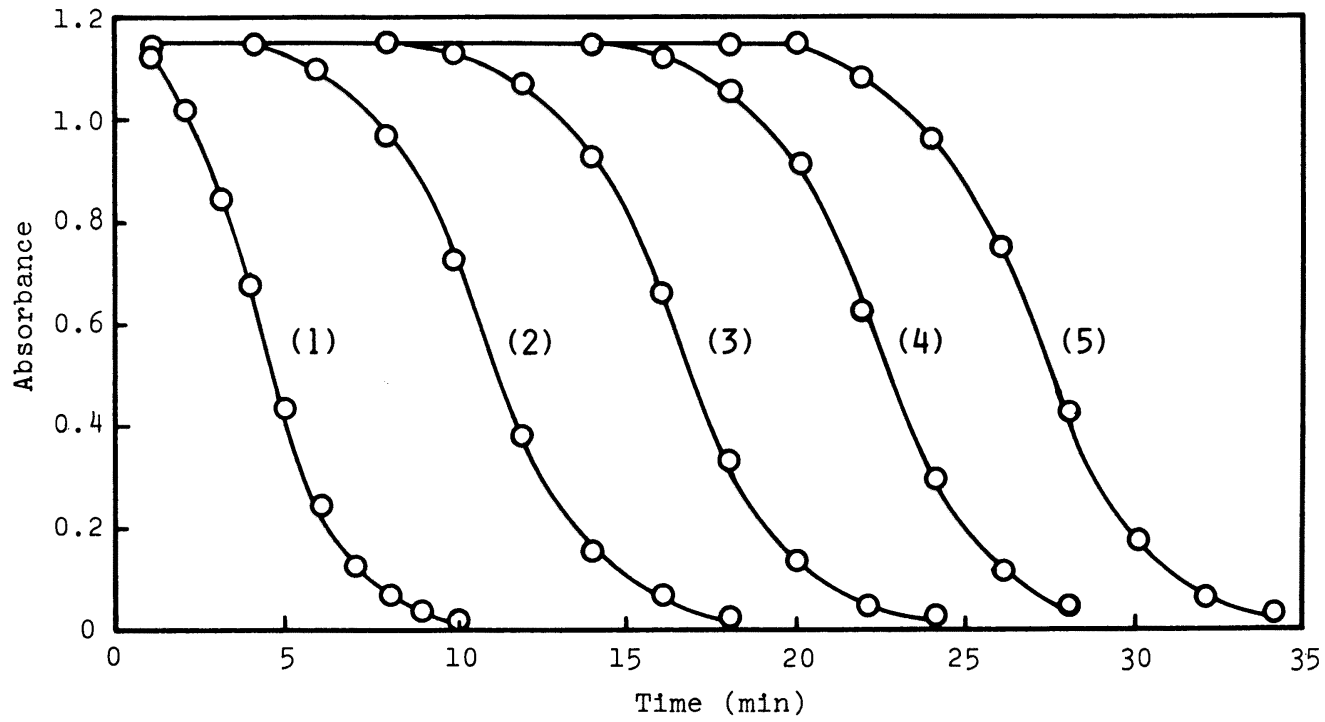

Fig. 2 Reaction rate curves (Temperature; $25^{\circ} \mathrm{C}$ )

$\mathrm{NO}_{2}^{-}$: (1) $10 \mathrm{ppm}$, (2) $1 \mathrm{ppm}$, (3) $0.1 \mathrm{ppm}$, (4) $0.01 \mathrm{ppm}$, (5) dist1lled water. 
3.2.1 The reaction rate The kinetic reactions were examined for each solution $\left(10.0 \mathrm{~cm}^{3}\right.$ ) containing $10,1,0.1$ or $0.01 \mathrm{ppm}$ nitrite ions and for distilled water. The curves shown in Fig. 2 were obtained by measuring the absorbance of these solutions at various reaction time. In the absence of nitrite ions(curve 5 in Fig. 2), the color-fading of the iron(III) thiocyanate complex began approximately 20 min after the initiation and the solution became almost colorless after $32 \mathrm{~min}$. In the presence of nitrite ions, the color-fading was accelerated with increasing nitrite ion concentration. These results indicate that the length of the induction period is greatly affected by the concentration of nitrite ions, and that nitrite ions ranging in concentration from 0.0005 to $10 \mathrm{ppm}$ can be determined by measuring the absorbance at different reaction time.

This kinetic reaction rate depended not only on the concentration of nitrite present, but also on the concentration of iodide and nitric acid, and especially on the temperature.

Commercially available nitric acid usually contains trace amounts of nitrite ions as impurity. If such nitric acid is used as a reagent, it is found impossible to determine nitrite ion concentration of less than $0.01 \mathrm{ppm}$ in a sample. Nitrite ions in $100 \mathrm{~cm}^{3}$ iron(III) reagent solution was found, however almost completely decomposed by using $10 \mathrm{mg}$ of urea and by heating for $10 \mathrm{~min}$.

3.2.2 The effect of various ions Metal ions, such as silver, mercury (II) and iron(II) interfered with the determination of nitrite ion. Oxidizing or reducing anions, such as chromate, sulfide, sulfite, thiosulfate and cyanide in 0.1 to $1 \mathrm{ppm}$ level also interfered.

\section{Determination of Bromide}

The oxidation reaction between iodide and potassium permanganate in an acid medium is shown in Eqs. (1) and (2).

$$
\begin{aligned}
& 10 \mathrm{I}^{-}+2 \mathrm{MnO}_{4}^{-}+16 \mathrm{H}^{+} \longrightarrow 5 \mathrm{I}_{2}+2 \mathrm{Mn}^{2+}+8 \mathrm{H}_{2} \mathrm{O} \\
& \mathrm{I}_{2}+2 \mathrm{MnO}_{4}^{-}+4 \mathrm{H}^{+} \frac{\mathrm{Br}^{-}}{\text {catalyst }} 2 \mathrm{IO}_{3}^{-}+2 \mathrm{Mn}^{2+}+2 \mathrm{H}_{2} \mathrm{O}
\end{aligned}
$$

The author and others found that the reaction (1) is very fast compared to the reaction (2), which is catalytically prompted by the presence of trace amounts of bromide ion. The catalytic effect of chloride is weaker than that of bromide. The catalytic reaction has been studied colorimetrically and a new method for the determination of bromide established ${ }^{9}$.

\subsection{Procedure}

To $10.0 \mathrm{~cm}^{3}$ of the sample, add $1 \mathrm{~cm}^{3}$ of the potassium iodide solution(1 $\mathrm{mg} \mathrm{I}^{-}$ $/ \mathrm{cm}^{3}$ ) and $0.7 \mathrm{~cm}^{3}$ of sulfuric acid solution(1:1), and then mix. Place the solution in a water bath at $15^{\circ} \mathrm{C}\left(\right.$ or at $25^{\circ} \mathrm{C}$ ) for about $15 \mathrm{~min}$. Start the reaction by adding $0.7 \mathrm{~cm}^{3}$ of the potassium permanganate solution $\left(0.04 \mathrm{~mol} \mathrm{dm}^{-3}\right)$. Mix thoroughly and let the solution stand in the water bath. Exactly $3.5 \mathrm{~min}(\mathrm{or} 70 \mathrm{~s})$ after the addition of the potassium permanganate solution, add $5 \mathrm{~cm}^{3}$ of carbon tetrachloride and immediately shake the mixture for $30 \mathrm{~s}$ in order to extract the remaining free iodine. After the phase separation, transfer the organic layer to a $50 \mathrm{~cm}^{3}$ separatory funnel. To the organic layer, add $5 \mathrm{~cm}^{3}$ of water, $1 \mathrm{~cm}^{3}$ of the

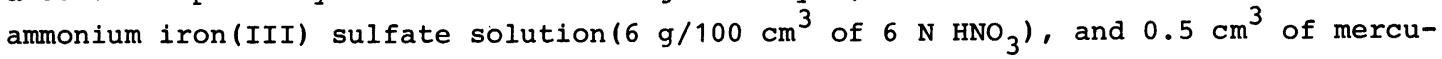


ric thiocyanate solution $\left(0.3 \mathrm{~g} / 100 \mathrm{~cm}^{3}\right.$ of ethanol), and shake the separatory funnel for about one min. The aqueous layer is thus colored with iron(III) thiocyanate.

$$
\begin{aligned}
& 6 \mathrm{I}_{2}+7 \mathrm{Hg}(\mathrm{SCN})_{2}+8 \mathrm{H}_{2} \mathrm{O} \longrightarrow 6 \mathrm{HgI}_{2}+\mathrm{Hg}(\mathrm{CN})_{2}+2 \mathrm{SO}_{4}^{2-}+16 \mathrm{H}^{+}+12 \mathrm{SCN}^{-} \\
& \mathrm{SCN}^{-}+\mathrm{Fe}^{3+} \rightleftarrows \mathrm{FeSCN}^{2+}
\end{aligned}
$$

Measure the absorbance of the aqueous layer at $460 \mathrm{~nm}$.

4.2 Some experimental results

4.2.1 The calibration curve The calibration curves shown in Fig. 3 were obtained by the procedure described above using $10 \mathrm{~cm}^{3}$ of standard bromide, chloride and bromide in the presence of $10 \mathrm{ppm}$ chloride. Chloride gives a curve similar to bromide when the concentrations of chloride are more than a hundred times as much as bromide. As natural waters always contain small amounts of chloride, the determination of bromide in the presence of chloride was also investigated ${ }^{9)}$. The bromide contents in natural waters such as rain water and river water were determined successfully by the calibration curves.

The same calibration curve as that for bromide is also obtained for bromate solutions with concentrations given as bromine.

4.2.2 The effect of various ions Sulfide, thiosulfate, thiocyanate and cyanide ions interfered with the determination of bromide. Silver and mercury(II) ions interfered strongly.

\subsection{Applications}

The determination of bromine in silicate rocks Takahashi et al. ${ }^{10}$ ) have reported the photometric determination of micro amounts of bromine in silicate rocks by means of its catalytic effect. They have first investigated in detail the iodine-potassium permanganate reaction in the presence of bromide as a catalyst ${ }^{9)}$ and have established optimum conditions for the determination of bromine. They found that the log absorbance vs the concentration of the catalyst yields a linear relationship at a constant reaction time.

The determination of bromine in silicate rocks consists of decomposing the silicate rock sample by fusion

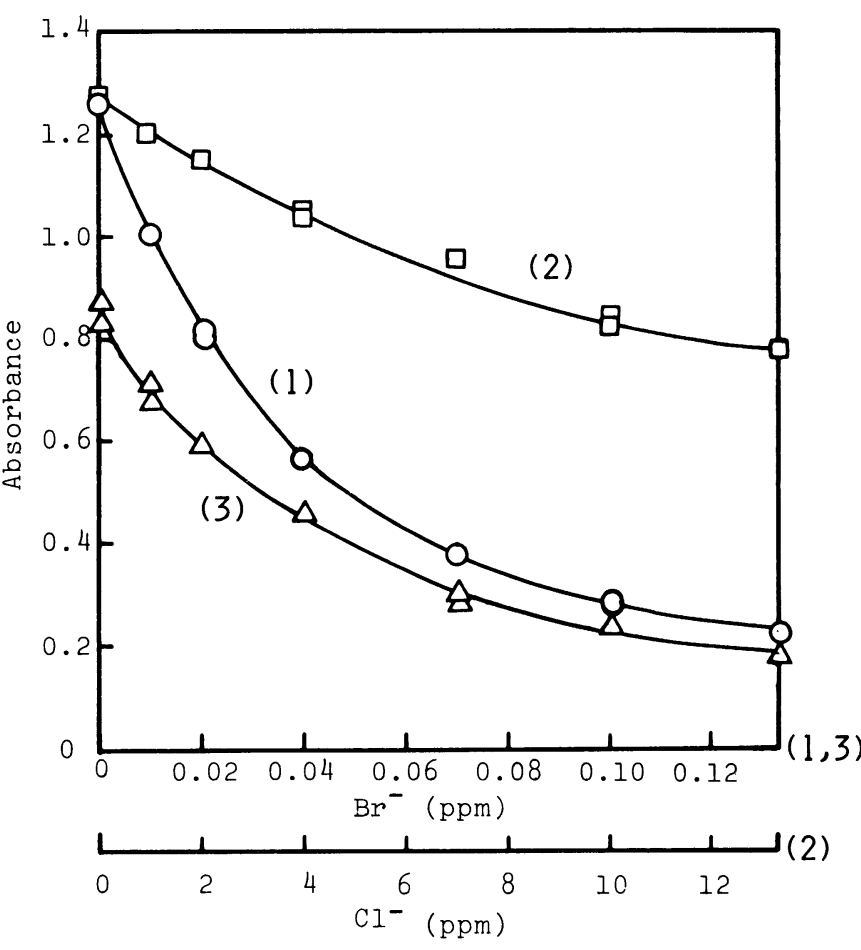

Concentration of $\mathrm{Br}^{-}$or $\mathrm{Cl}^{-}$

Fig. 3 Calibration curves

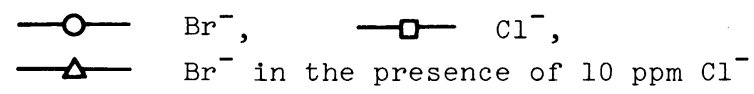

Reaction temp.; $15{ }^{\circ} \mathrm{C}$, Reaction time; $3.5 \mathrm{~min}$ 
with potassium hydroxide, leaching the melt with water, oxidizing bromide to bromine with potassium permanganate ${ }^{11}$, extracting by benzene, back extracting by sodium hydroxide solution, and finally determining the bromine by the improved catalytic method. In this way, $0.25 \sim 0.5 \mathrm{~g}$ rock samples with more than 0.04 ppm bromine can be analyzed accurately.

4.4 Another catalytic method

By a further investigation of the oxidation of iodine to iodate with various oxidizing agents, the author et al. ${ }^{12)}$ found that, when ammonium cerium(IV) sulfate is used as the oxidizing agent, this oxidation reaction is catalytically promoted by trace amounts of bromide in the presence of a large amount of potassium dichromate in nitric acid solution. This reaction proceeds fairly slowly at room temperature, so that favorable conditions for the procedure can be realized. A new method for the determination of a minute amount of bromide using this reaction has been studied.

\section{Determination of Thiosulfate, Thiocyanate and Sulfide}

Iodine does not react with sodium azide, but the following reaction is catalytically promoted by the presence of micro amounts of sulfur compounds such as thiosulfate, thiocyanate and sulfide.

$$
2 \mathrm{NaN}_{3}+\mathrm{I}_{2} \longrightarrow 2 \mathrm{NaI}+3 \mathrm{~N}_{2}
$$

This catalytic reaction has been applied to the photometric determinations of ultramicro amounts of thiosulfate ${ }^{13)}$, thiocyanate ${ }^{14}$ ) and sulfide ${ }^{15}$.

The catalytic reaction proceeds at a very fast rate compared to the ordinary catalytic reaction, so that the reaction may terminate within a short period of time. However, the extent of the catalytic reaction depends on the concentration of catalyst. The reaction is also slightly affected by temperature.

\subsection{Procedure and results}

5.1.1 The determination of thiosulfate One $\mathrm{cm}^{3}$ of an aqueous solution $\left(1 / 6 \times 10^{-3} \mathrm{~mol} \mathrm{dm} \mathrm{d}^{-3}\right.$ in $\mathrm{KIO}_{3}$ and $1 \mathrm{~mol} \mathrm{dm^{-3 }}$ in $\left.\mathrm{KI}\right)$ is placed in a glass tube with a glass stopper, and $1 \mathrm{~cm}^{3}$ of $1 \mathrm{~mol} \mathrm{dm}$ acetic acid is added in order to liberate iodine $\left(\mathrm{IO}_{3}^{-}+5 \mathrm{I}^{-}+6 \mathrm{H}^{+} \longrightarrow 3 \mathrm{I}_{2}+3 \mathrm{H}_{2} \mathrm{O}\right)$. The iodine reacts with the large excess of iodide to form triiodide ion which has a maximum absorbance at $350 \mathrm{~nm}\left(\mathrm{I}_{2}+\mathrm{I}^{-} \rightleftarrows \mathrm{I}_{3}^{-}\right)$. Then $3 \mathrm{~cm}^{3}$ of sodium azide solution $\left(20 \mathrm{~g} / 100 \mathrm{~cm}^{3}\right)$ are added. To the solution which is kept at $25^{\circ} \mathrm{C}, 5 \mathrm{~cm}^{3}$ of the sample solution is added and mixed. At 3 min after the mixing, the absorbance of the remaining triiodide ion is measured at $350 \mathrm{~nm}$.

The calibration curve was in a good linear relationship for the concentration range from 0.01 to $0.15 \mathrm{ppm}$ of thiosulfate ions.

Copper, iron(III), sulfite and cyanide ions interfered.

5.1.2 The determination of thiocyanate one $\mathrm{cm}^{3}$ of a mixed reagent solution (1/6 $\times 10^{-3} \mathrm{~mol} \mathrm{dm}^{-3}$ in $\mathrm{KIO}_{3}$ and $1 \times 10^{-2} \mathrm{~mol} \mathrm{\textrm {dm } ^ { - 3 }}$ in $\mathrm{KI}$ ) and $0.5 \mathrm{~cm}^{3}$ of $1 \mathrm{~mol}$ $\mathrm{dm}^{-3}$ acetic acid are placed in a glass tube. After standing this solution for 5 min at $25^{\circ} \mathrm{C}, 3 \mathrm{~cm}^{3}$ of sodium azide solution $\left(20 \mathrm{~g} / 100 \mathrm{~cm}^{3}\right)$ and $5 \mathrm{~cm}^{3}$ of the sample

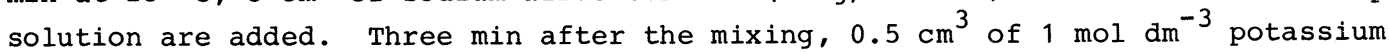
iodide solution is added. Then, the absorbance of the solution is measured at 
$350 \mathrm{~nm}$.

According to this method, the concentration ranging from 0.005 to $0.08 \mathrm{ppm}$ of thiocyanate ion in $5 \mathrm{~cm}^{3}$ of the sample can be determined accurately.

When the concentration of potassium iodide in the mixed reagent solution is

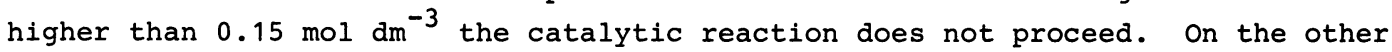
hand, the triiodide ion is quantitatively formed by the presence of more than 0.05 mol $\mathrm{dm}^{-3}$ iodide in the final solution. Therefore, two step adjustment of lodide concentration was essential for the determination of thiocyanate (See procedure).

\section{1 .3 The determination of sulfide The sample solution $\left(10 \mathrm{~cm}^{3}\right)$ is placed} in a $15 \mathrm{~cm}^{3}$ glass centrifuge tube containing a precipitate of basic zinc carbonate formed by mixing $0.5 \mathrm{~cm}^{3}$ of zinc nitrate solution $\left\{3 \mathrm{~g} \mathrm{Zn}\left(\mathrm{No}_{3}\right)_{2} \cdot 6 \mathrm{H}_{2} \mathrm{O} / 100 \mathrm{~cm}\right\} \mathrm{with}$ $0.5 \mathrm{~cm}^{3}$ of sodium carbonate solution(1.5 $\mathrm{g} \mathrm{Na}_{2} \mathrm{CO}_{3} / 100 \mathrm{~cm}^{3}$ ) and $0.5 \mathrm{~cm}^{3}$ of formaldehyde solution $\left(\begin{array}{ll}37 & \%\end{array}\right)$. After shaking, the precipitate containing $z$ inc sulfide is separated by centrifugation. Then $5 \mathrm{~cm}^{3}$ of water is added to the precipitate, and the content is shaken vigorously. Three $\mathrm{cm}^{3}$ of the sodium azide solution $(20 \mathrm{~g} / 100$ $\mathrm{cm}^{3}$ ) and $2 \mathrm{~cm}^{3}$ of the triiodide solution, which is prepared by mixing a mixed rea-

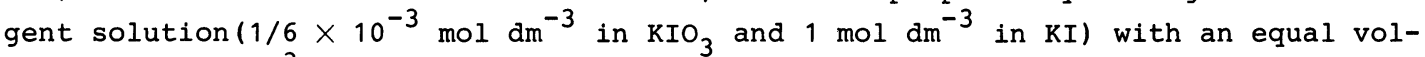

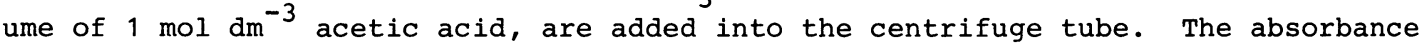
is measured at $350 \mathrm{~nm}$ at 5 min after the addition of triiodide solution. According to this method, sulfide ion in the concentration range from 2 to $25 \mathrm{ppb}$ can be determined. An interference of sulfite ion is removed by the addition of formaldehyde solution.

\section{Determination of Cyanide}

Guilbault et al. ${ }^{16)}$ have reported a sensitive, specific method for cyanide using catalytic reaction. p-Nitrobenzaldehyde reacts with cyanide to give intermediate cyanohydrin. The cyanohydrin produced reacts with o-dinitrobenzene to give a highly colored blue compound. Because cyanide is regenerated, a cataly.tic reaction occurs with increased sensitivity.

The author et al. ${ }^{17)}$ have investigated in detail the catalytic reaction and have established the method for the determination of ultramicro amounts of cyanide.

6.1 Procedure and results

In a $20 \mathrm{~cm}^{3}$ test tube are placed $2 \mathrm{~cm}^{3}$ of $0.2 \mathrm{~mol} \mathrm{dm} \mathrm{dm}^{-3} \mathrm{p}$-nitrobenzaldehyde in methyl cellosolve, $2 \mathrm{~cm}^{3}$ of $0.15 \mathrm{~mol} \mathrm{dm}$ o-dinitrobenzene in methyl cellosolve and $2 \mathrm{~cm}^{3}$ of $0.1 \mathrm{~mol} \mathrm{dm} \mathrm{dm}^{-3}$ sodium hydroxide solution containing cyanide ion. The mixture is allowed to stand for $20 \mathrm{~min}$ at $25^{\circ} \mathrm{C}$ or for $60 \mathrm{~min}$ at $35^{\circ} \mathrm{C}$. The absorbance of the colored solution is measured at $555 \mathrm{~nm}$ with $1 \mathrm{~cm}$ cell against water. One to $100 \mathrm{ng}$ of cyanide in $2 \mathrm{~cm}^{3}$ of the sample solution was determined by this way. As low as $0.01 \mathrm{ppm}$ of cyanide in the waste water was also determined accurately.

Hypochlorite, sulfide, acetone, formaldehyde and metal ions such as Co(II), $\mathrm{Hg}(\mathrm{II})$ and $\mathrm{Cu}$ (II) which form complexes with cyanide interfered with the determination of cyanide.

\section{Dtermination of Fluoride}

The red complex between Xylenol orange(XO) and zirconium ions has a maximum absorbance at about $550 \mathrm{~nm}$. The author et al. ${ }^{18)}$ found that the binary (Zr-Xo) com- 
plex reacts with cetyltrimethylammonium chloride(CTC) to form a ternary comlex which has a maximum absorbance at $605 \mathrm{~nm}$ and a high molar absorptivity. West et al. 19) have reported a spectrophotometric method for the determination of fluoride which is based on the catalytic effect of fluoride on the slow reaction between $x$ and slightly hydrolyzed zirconium solution. A more sensitive method ${ }^{18}$ ) has been developed for the determination of ultramicro amounts of fluoride based on the above catalytic reaction in the presence of CTC.

\subsection{Procedure}

A $10 \mathrm{~cm}^{3}$ of the sample solution containing less than $100 \mathrm{ppb}$ of fluoride, 1 $\mathrm{cm}^{3}$ of $2 \times 10^{-4} \mathrm{~mol} \mathrm{\textrm {dm } ^ { - 3 }}$ xO and $1 \mathrm{~cm}^{3}$ of $0.1 \% \mathrm{CTC}$ (in $3 \mathrm{~N} \mathrm{HCl}$ ) solutions are placed in a test tube. One $\mathrm{cm}^{3}$ of $2 \times 10^{-4} \mathrm{~mol} \mathrm{\textrm {dm } ^ { - 3 }}$ slightly hydrolyzed zirconium solution (in $0.02 \mathrm{~N} \mathrm{HCl}$ ) is added. The solution is allowed to stand for $40 \mathrm{~min}$ at 25 ${ }^{\circ} \mathrm{C}$, and the absorbance is measured at $605 \mathrm{~nm}$ against water.

As low as $10 \sim 100 \mathrm{ppb}$ fluoride can be determined in this manner.

7.2 Some experimental results

7.2.1 Hydrolyzed zirconium

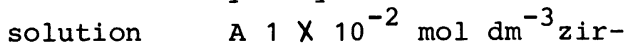
conium oxychloride stock solution(in $0.02 \mathrm{~N} \mathrm{HCl}$ ) was allowed to age for 4 hours at $40{ }^{\circ} \mathrm{C}$, being stored at about $5{ }^{\circ} \mathrm{C}$. The working solution of $2 \times 10^{-4} \mathrm{~mol} \mathrm{dm}^{-3}$ was prepared by diluting the stock solution with $0.02 \mathrm{~N}$ hydrochloric acid. This solution may be used for up to 7 days.

7.2.2 The reaction rate Reaction rate curves shown in Fig. 4 were obtained by measuring the absorbance of the solution at various time under the condition of procedure (7.1).

\subsubsection{The effect of various} ions Sulfate, phosphate, aluminum and iron(III) showed interferences in this method.

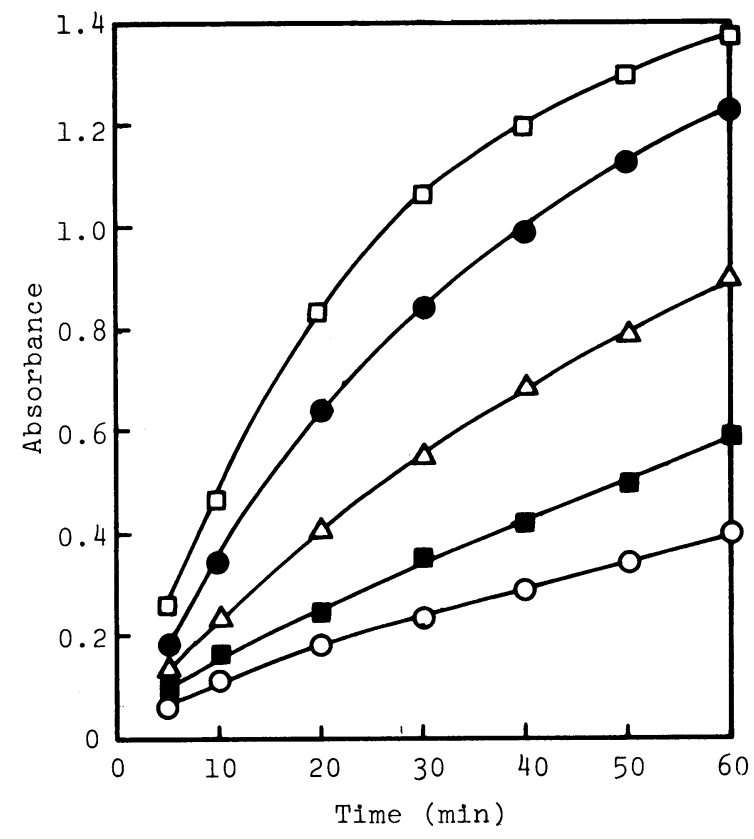

Fig. 4 Reaction rate curves

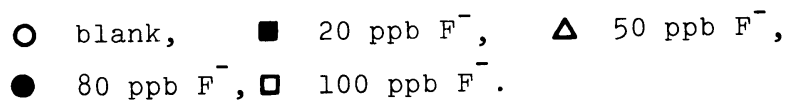

\section{References}

1) I.Iwasaki, S.Utsumi, T.Ozawa: Bull.Chem.Soc.Jpn., 26, 108 (1953).

2) S.Utsumi: Nippon Kagaku Zasshi, 74, 298(1953).

3) I.Iwasaki, S.Utsumi, T. Ozawa: Nippon Kagaku Zasshi, 78, 474(1957).

4) S.Utsumi, M.Shiota, N.Yonehara, I.Iwasaki: Nippon Kagaku Zasshi, 83, $32(1964)$.

5) I.Iwasaki, S.Utsumi, N.Yonehara: Nippon Kagaku Zasshi, 85, 36(1964).

6) N.Yonehara: Bull.Chem.Soc.Jpn., 37, 1101(1964).

7) N.Yonehara, M.Yoshida, I.Iwasaki: Bull.Chem.Soc.Jpn., 433, $3796(1970)$. 
8) S.Utsumi, T.Okutani, A.Sakuragawa, A.Kenmotsu: Bull.Chem.Soc.Jpn., 51, 3496 (1978).

9) M.Shiota, S.Utsumi, I.Iwasaki: Nippon Kagaku Zasshi, 80, 753(1959).

10) K.Takahashi, M.Yoshida, T.Ozawa, I.Iwasaki: Buli.Chem.Soc.Jpn., 43, $3159(1970)$.

11) I.Iwasaki, S.Utsumi, A.Tomonari, I.Morita: Nippon Kagaku Zasshi, 80, 744(1959).

12) N.Yonehara, S.Utsumi, I.Iwasaki: Bull.Chem.Soc.Jpn., 38, 1887(1965).

13) S.Utsumi, T.Okutani: Nippon Kagaku Kaishi, 1973, 75.

14) S.Utsumi, T.Okutani, T.Yamada: Bunseki Kagaku, 24, 799 (1975).

15) A.Sakuragawa, T.Harada, T.okutani, S.Utsumi: Bunseki Kagaku, 29, $264(1980)$.

16) G.G.Guilbault, D.N.Kramer: Anal.Chem., 38, 834 (1966).

17) T.Okutani, H.Kotani, S.Utsumi: Bunseki Kagaku, 26, $116(1977)$.

18) Unpublished research. T.Okutani, M.Tsukada, A.Sakuragawa, S.Utsumi: Partly presented at the 29th Annual Meeting of the Japan Society for Analytical Chemistry, Fukuoka, October, (1980).

19) M.L.Cabello-Tomas, T.S.West: Talanta, 16, 781(1969).

Keyword phrases

spectrophotometric determination; catalytic method;

iodide and iodate, nitrite, bromide, thiosulfate,

thiocyanate, sulfide, cyanide, fluoride.

(Received Aug. 28, 1981) 